\title{
Integrated Social Media into Mobile-Assisted Foreign Language Learning
}

\author{
Ling Luo ${ }^{1}$
}

\begin{abstract}
In today's college campuses, having a smartphone and being active on social media has become a fashion. Though many mobile apps have been designed for learning languages, there are few studies on applying social media based mobile apps to promote the effective learning of foreign languages. As an emerging social media mobile app, WeChat is the most popular social tool in Chinese community around the world. The WeChat app has many communication functions: live chat, group chat, and multimedia input and document transmission, which are essential for language learning. In this research project, we integrate WeChat into a mobile-assisted Mandarin learning app that we have designed. WeChat and the mobile app allow effective communication among instructors and students, and student groups. It offers a variety of communication methods, including voice, text, graphic (abundant icons) and video, which fits the needs of language learning and practices. This integration between WeChat and the mobile app helps to expand the traditional language teaching and learning outside the classroom. Instructors can provide students instant instructions and feedback, and students can learn and practice the exercises anywhere. We have piloted this new approach and conducted various experiments in two sections of Chinese level I in a US college to assess its effectiveness.
\end{abstract}

\section{Key Words}

Social media, Mobile App, WeChat, Mandarin Chinese, Language learning

\footnotetext{
${ }^{1}$ Associate Professor, Modern Languages Department, The City University of New York (BMCC), NY, USA, email:
} LLUO@bmcc.cuny.edu 


\section{Introduction}

Current college-level Chinese language students belong to the cohort of Generation Z. An important characteristic of this generation is global, social, visual and technological. They are the most connected, educated and sophisticated generation ever. Generation $\mathrm{Z}$ is the first cohort to have Internet technology readily available at a young age (Prensky, 2001). As technology became more compact and affordable, the popularity of smartphones in the United States grew exponentially. Anthony Turner characterizes Generation $\mathrm{Z}$ as having a 'digital bond to the Internet', and argues that it may help young people to escape from the emotional and mental struggles they face offline (Borca et al., 2015).

In 2015, an estimated 150,000 apps were educational and aimed at children up to college level. The researchers and educators realize that young people use the Internet as a way to gain access to information and to interact with others. Mobile technology, social media, and Internet use have become increasingly important to modern adolescents over the past decade (Turner, 2015). Mobileassisted language learning (MALL) was first introduced in 1993 and became a sub-area of the growing field of mobile learning research. It has inspired learners to make use of the "anytime" and "anywhere" technology, the key concepts in MALL, in language learning, including the Rosetta Stone, Duolingo and Busuu. Though they prove to be effective to learn a language (Vesselinov, 2008, 2012 and 2016), the study only targets Spanish language and it does not target college students and their users are very motivated groups (only $45 \%$ of participants have completed the study and $70 \%$ of them have BA or higher degrees). In addition, these apps are not easily adopted within the college curriculum, because (a) the apps are designed for self-pace learning and not for use within the context of a course and the curriculum in the apps cannot be modified; (b) these language apps don't allow instructors to edit language content and customize exercises.

In order to tackle these challenges, we proposed a new MALL framework, which integrates a social media app WeChat, into a mobile language app called ICE to function for all learning activities.

\section{Literature Review}

\subsection{Mobile-assistant language learning}

While Mandarin is considered one of most difficult languages (according to the language difficulty rankings by US Foreign Service Institute), it is also one of the most popular foreign languages in the world. Unlike other foreign languages, we lack enough qualified instructors and supplementary teaching materials (Wen 2017). Mobile technology has become an essential element of our daily life. It has changed our lifestyle, and more importantly, our learning style.

Mobile-assisted language learning (MALL) was first introduced in 1993 and became a sub-area of the growing field of mobile learning research (Stockwell 2014, Burston 2014, McCarty 2017). It has inspired the learner to make use of this "anytime" and "anywhere" technology, the key concepts in MALL language learning. Thornton and Houser (2005) showed that mobile devices can indeed be effective tools for delivering language learning materials to the students. Studies have commonly emphasized the mobility of MALL devices, which allow learners to use the devices wherever and whenever they want. Learning, similarly, is not restricted to four-wall classrooms in this type of learning. This unique feature of mobile devices results in many other advantages in language learning (Cherian \& Williams, 2008; Chinnery, 2006; Kennedy \& Levy, 2008; Kukulska-Hulme, 2009; Power \& Shrestha, 2009; Wishart, 2008). 


\subsection{WeChat in Mandarin learning}

WeChat is a Chinese multi-purpose messaging, social media and mobile payment app developed by Tencent. It was first released in 2011, and by 2018 it was one of the world's largest standalone mobile apps by monthly active users with over 1 billion monthly active users - 902 million daily active users (Osman, 2011). WeChat provides many features that can be used for language learning, such as: text messaging, hold-to-talk voice messaging, broadcast (one-to-many) messaging, video calls and conferencing, video games, sharing of photographs and videos, and location sharing. Since smartphones and mobile social media platforms have become part of life and education amongst college students in the U.S., it is reasonable to expect that they would welcome WeChat as a part of their Chinese language learning.

WeChat has another important feature - a subscription account. WeChat users are allowed to create a subscription account, which enables them to push feeds to subscribers, interact with subscribers and provide them with services. This feature is very convenient for instructors to send messages and connect with the students. Under the traditional teaching mode, students rarely get first-hand teaching materials such as lesson plans and courseware. However, using a Wechat subscription account, teachers can push the prepared classroom materials to each student in time. It is convenient for students to check and verify immediately when they find problems. On the other hand, it is difficult for teachers to intervene in the after-school summarization stage (Chiang, 2013). After the introduction of WeChat teaching, any problems encountered by students in the class can be answered quickly. Teachers can guide students in a timely and effective manner.

\subsection{Proposed method}

Due to the limitations of current language learning mobile apps, we have designed an app called ICE and then integrated Webchat's functions to assist students to learn Mandarin. ICE allows the instructor to assign exercises via a mobile app, while WeChat enables the instructor to assign audio and video exercises where students and instructor have direct communication via WeChat.

\section{Methodology}

\subsection{Integration of ICE and WeChat}

To tackle the above problems, we have developed a mobile app called ICE that combines with WeChat to teach Mandarin (iChinese Exercise on Android and iOS) since 2016. We are conducting preliminary experiments in a Chinese I class and ICE and WeChat received positive feedback from student participants for its ease of use and instant feedback.

Compared to the regular MALL apps, the integration of ICE and WeChat has three unique features:

(a) ICE allows instructors to customize learning materials according to the adopted textbook; hence, it seamlessly aligns with the curriculum

(b) WeChat allows instructors to assign and grade exercises of listening and speaking, and students easily submit their answers and receive feedback from the instructor

(c) WeChat allows students to chat with the instructor (1 Vs 1 ) and their classmates (1 vs N), hence it extends the classroom learning outside the classroom. 

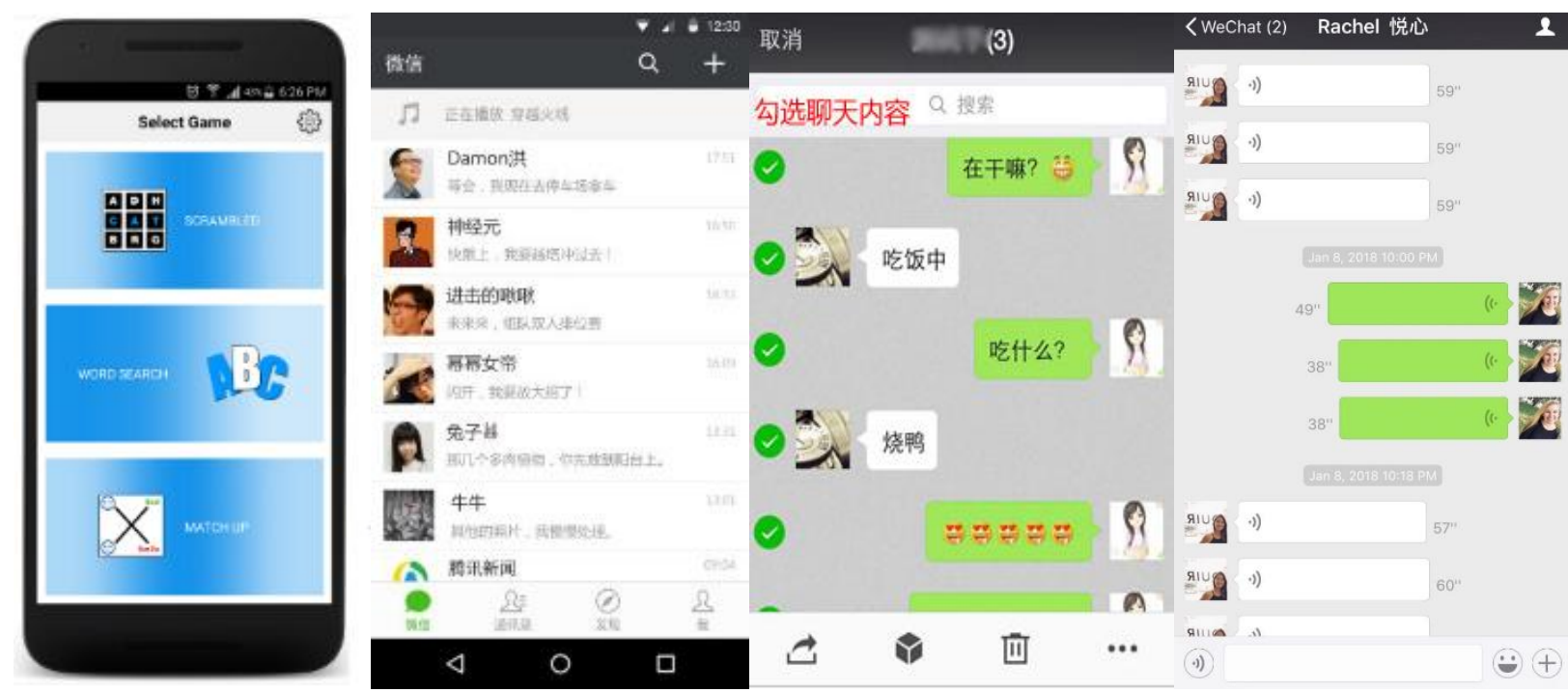

Figure 1. The interface of ICE mobile app and Wechat. a) three different mini-games available for students practicing vocabulary and sentences, b) the main interface of the Wechat app, c) The screenshot of text message on WeChat, and d) The screenshot of voice message on WeChat.

ICE includes two modules, the instructor web portal and the student mobile app. In the mobile app, all the exercises will be available for student to preview, review and post-review. Currently, there are three simple games-based exercises available (Figure 1a). The instructor's web portal (Figure 1b) allows instructors to customize language materials, which includes vocabulary, sentences and grammar. Whenever the instructors assign exercises via ICE, the students receive notifications via WeChat text messages and start working on it at any time and any location with any number of attempts. The grades will be available to the instructor via web portal.

In order to use WeChat, we first set up a WeChat group in the class. All the students in a same class join a group and get the same information at the same time; there are various functions of WeChat to learn Chinese as presented below:

1. Instructors distribute learning materials, especially multimedia materials, such as video and audio.

2. Students submit their video and audio assignment via WeChat (Figure 2a and 2b).

3. Students share their learning experiences with their classmates.

4. Students receive feedback from the instructor and classmates.

5. Besides the group activities, students still can have communication one-to-one with the instructor and other classmates. 


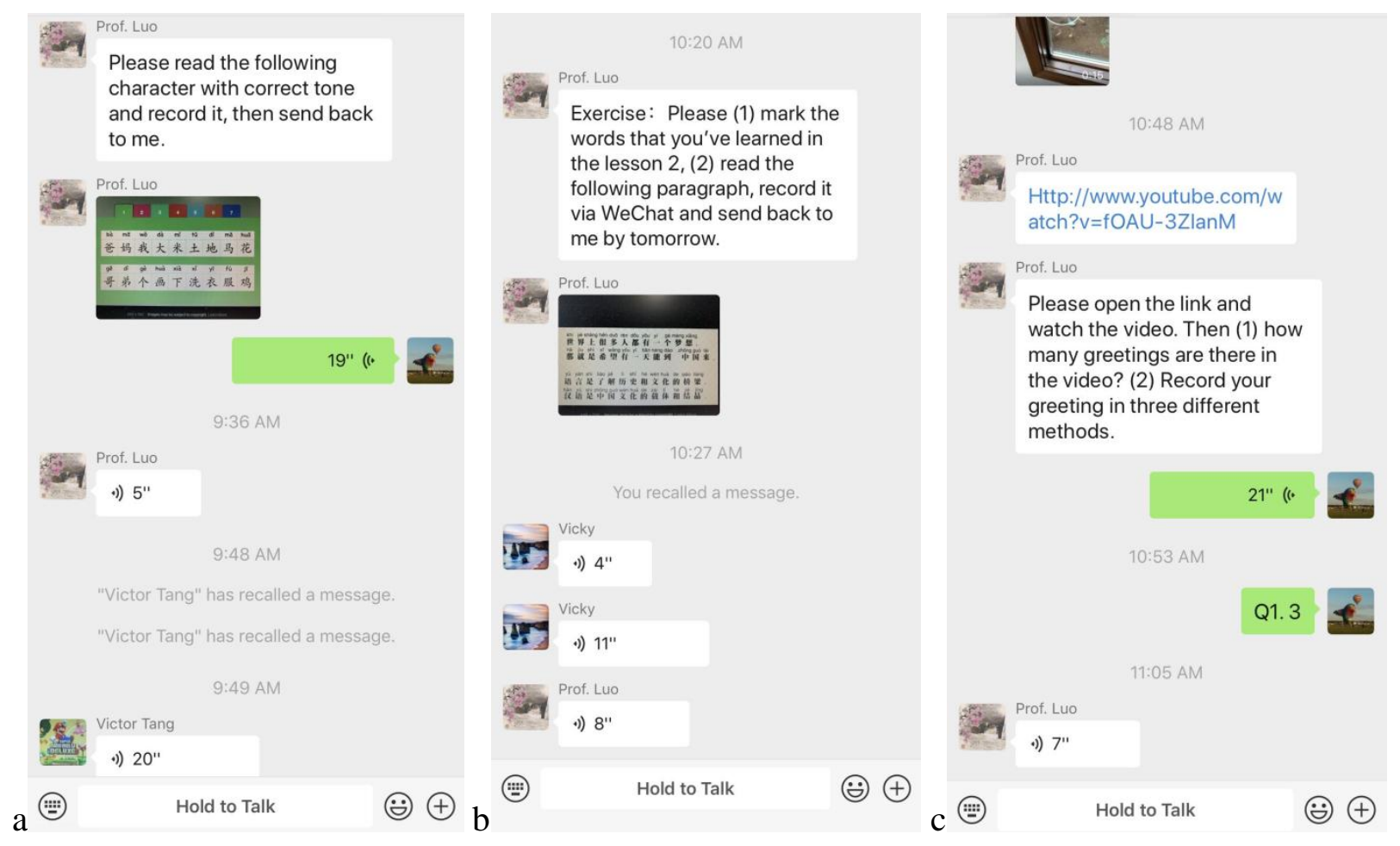

Figure 2. Screenshot of different exercises using WeChat. a) students practice pinyin and tones by voice recording via WeChat; b) students practice pinyin and Chinese characters via voice recording via WeChat; c) students watch a Youtube video of authentic Chinese greetings and then practice greetings in Chinese via WeChat.

Beside exercises in a textbook or workbook, WeChat also allows instructors to easily include other supplementary learning materials into the language learning. Two examples listed are as follows:

Example 1: an instructor plans to share a handout (问候 greeting) from a book, he/she can simply take a picture of the handout and share the picture in the WeChat group.

Example 2: an instructor can send students a video as supplementary learning material "The song of the number", (Figure 2c) the students can follow the video to practice how to count numbers in Chinese. After the students finish learning exercises, they can record their speech and send back to the instructor to get the quick feedback through WeChat video/voice chat.

ICE and WeChat are very useful to help students to improve their language skills. Besides the content of the materials, the students can use it whenever they have time. This benefit is very important in language learning.

After the students finish an exercise, they can record what they learnt and send back to the instructor to get the feedback through WeChat video and voice chat. For example: when students are learning Pinyin, the instructor can send students an exercise to practice pinyin and tones (Figure 2a). Students will practice both pinyin and Chinese characters learned in the class (Figure 2b). In Figure 2c, students watch a video which includes four authentic Chinese greetings that are not used very often, afterwards students are asked to record three greetings in Mandarin.

${ }^{2} \mathrm{https} / / / \mathrm{www}$.youtube.com/watch?v=27c2kSVNU4U 


\section{Experiments}

Given the ethical concerns to have one group of students potentially advantaged by the use or nonuse of a technology, we will use a matrix approach, where the two different groups are given access to the app at different times during the course (before and after the $8^{\text {th }}$ week). Both groups of students have had access to the same technology, the timing in which this access occurs is necessarily going to have some kind of effect, be it on the content which is taught.

\section{Experimental design}

In the spring semester of 2018 (15 weeks) and the fall semester of 2018 ( 15 weeks), we chose a Chinese I class, 30 students in each class, to conduct our experiment. We split one class into two groups, each group will have 15 students. One group was given access to the app and using WeChat before the $8^{\text {th }}$ week. They used the app to practice out of classroom and complete their homework; while another group was assigned regular homework and exercises. After the $7^{\text {th }}$ week, two groups are switched.

Here are two quizzes to test how the students performed after they used App and WeChat.

Quiz 1: Write the following words in Chinese according to the English meaning.
1. student
2. he/him
3. teacher
4. you
5. good/fine

This quiz would check the students' performance after they practiced all exercises via ICE. The result of two semesters is as follows: (Figure 3)

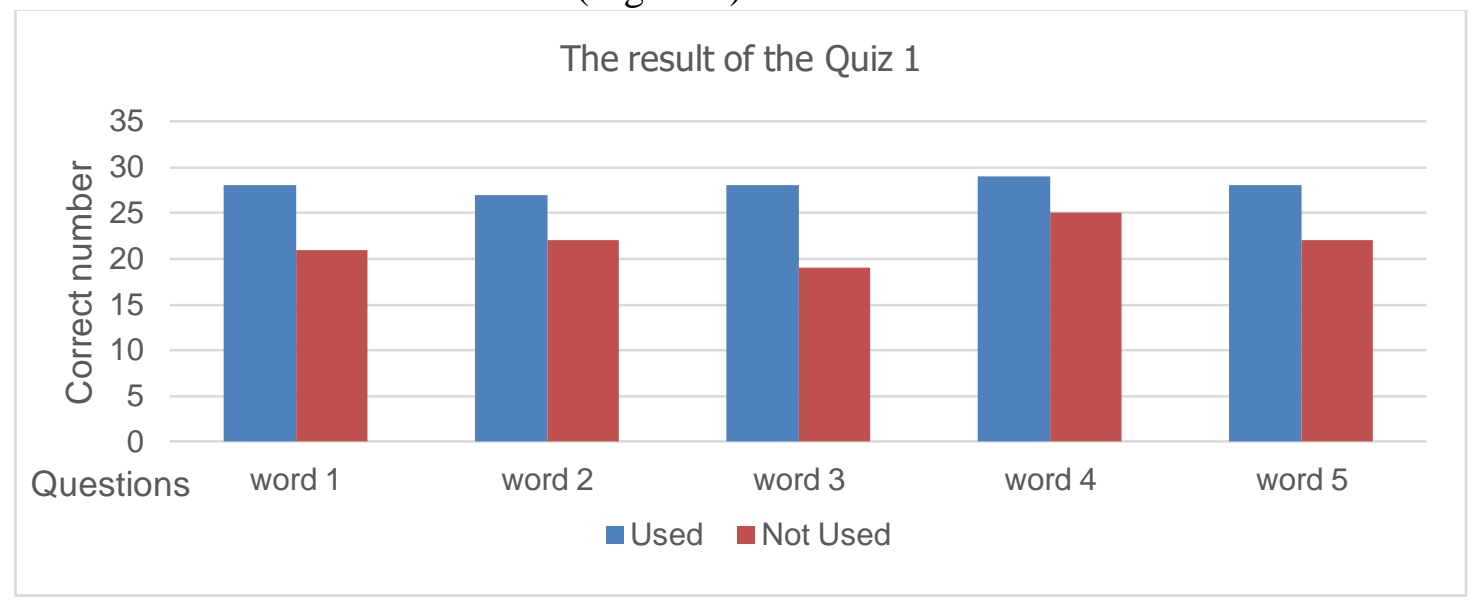

Figure 3. The comparison of result of quiz 1 . The students used the apps did a better job for all 5 questions (blue bars) than the students who did not use the apps. 
Quiz 2: Record the answers in full Chinese sentence after you listen to the question.

\section{1. 你贵姓?}

\section{2. 你叫什么名字?}

3. 你是学生吗?

\section{4. 她是谁?}

\section{5. 你的中文名字是什么?}

This quiz would check the students' performance after they practiced all exercises via ICE. The result of two semesters is showed below (Figure 4).

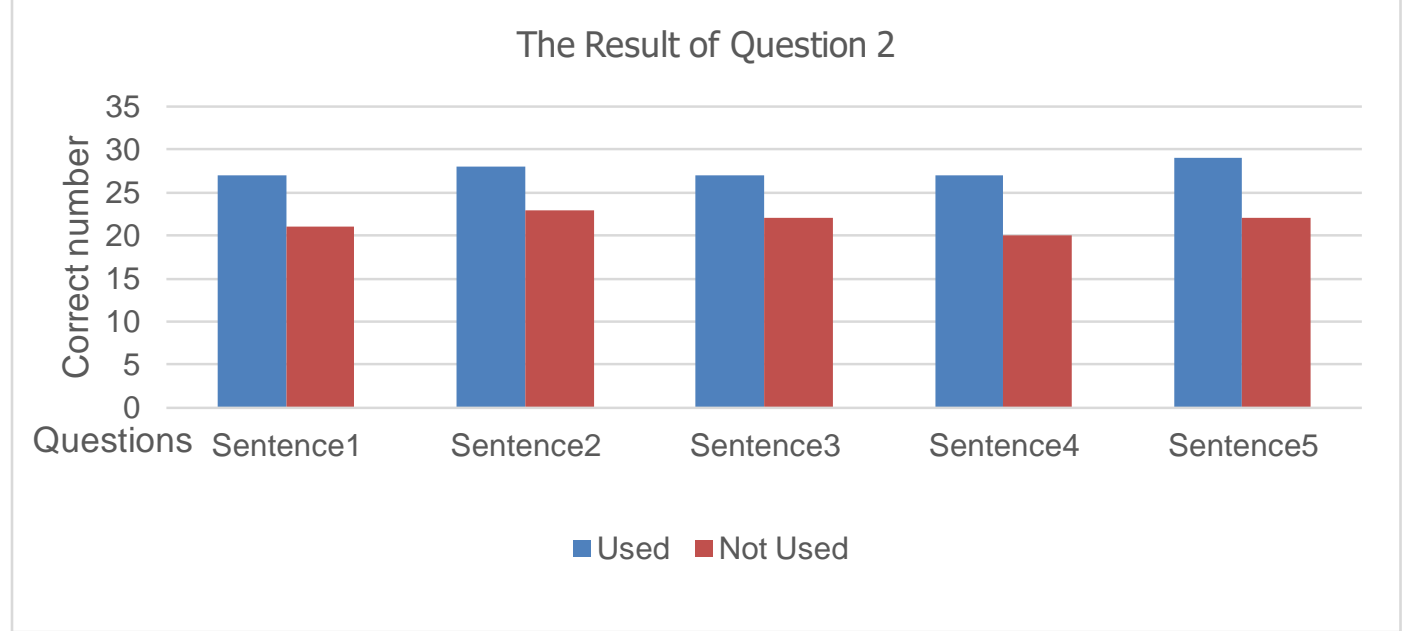

Figure 4. The comparison of result of quiz 2. The students used the apps did a better job for all 5 questions (blue bars) than the students who did not use the apps.

The exam score of students using ICE and WeChat before the exam are the results from the experimental group, the exam score of students without using the app before the exam are results of the control group. The final exam covers lesson 1-6. We used Chinese Link (2010) as our textbook.

The routine works that have been assigned to the students to use ICE and WeChat are:

1) Assign new vocabulary in the web-portal and then ICE generates new exercise of the vocabulary for students.

2) Students start to do the exercises on the App, and then record the new vocabulary or sentences using WeChat and submit to instructor.

3) Instructor gives an instant feedback to student according to the recording using WeChat.

4) Students continue to work on their assignment in ICE, and record short audio and video exercise using the new vocabulary and sentences to the instructor on WeChat.

5) Instructor will select and share some student's work in the WeChat group.

6) All the students can give their feedback and comments to other student's work in the WeChat group. Each one is required to submit feedback of two questions submitted by other students. 
The goal we designed ICE and WeChat is to test how they support foreign language teaching. ICE can be used to distribute reading and writing assignments to students. WeChat can be used to assign the listening and speaking assignments to students. Listening, speaking, reading and writing are the four aspects of language learning. We use both of ICE and WeChat to assist students to learn the foreign language from various aspects.

\section{Analysis}

In this section the formative and/or summative assessment strategies to measure research outcomes and the effectiveness of the experimental design are discussed.

The design of the exam questions goes as follows: Students should be familiar with the meaning, know words related to the term (phrase and sentence), and have flexibility with using it in both written and oral forms. It is clear that to master a word is more than to know its definition. The following five dimensions theory (Cronbach, 1942) were used to create the exam questions:

- Generalization: The ability to define a word

- Application: Selecting an appropriate use of the word

- Breadth: Knowledge of multiple meanings of the word

- Precision: The ability to apply a term correctly to all situations

- Availability: The ability to use the word productively

The statistical analysis of exam scores: the dependent variable is the score statistics of both exams between two groups. After the final exam, I collected the final grades of all students and made a comparison. 60 students took the test, which included 30 students who used ICE App and WeChat, and other 30 students who didn't. The comparison of the data is visible in the following chart (Figure 5).

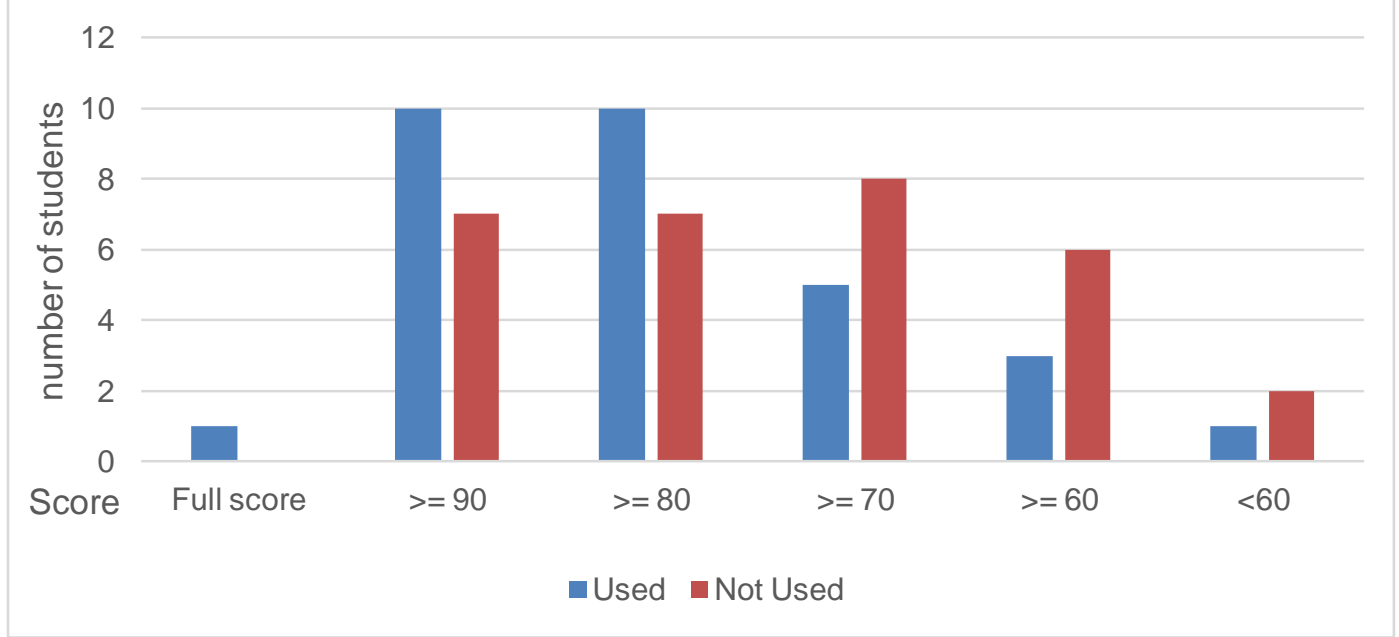

Figure 5. The result of the final Exam.

The average scores of the final exam are 84.5 (using the apps) vs 77.6 (without using the apps) and the full credit is 100 . The result analysis clearly shows the students that used the apps performed better than the students that didn't use the apps. 
Additionally, at the end of each semester, we also conducted a survey. Table 3 shows the result of the survey.

- Number of students who participated: 60

- Age of participants: first year Chinese language students

- Level of language: 1

- Number of valid surveys: 58

Table 1: The survey result

\begin{tabular}{|c|c|c|c|}
\hline Interesting to play & Easy to play & Benefit for learning & Want to play more \\
\hline 46 & 52 & 42 & 58 \\
\hline $79.3 \%$ & $89.6 \%$ & $72.4 \%$ & $82.7 \%$ \\
\hline
\end{tabular}

\section{Conclusion and Future Work}

In this project, we integrated a social media app WeChat into a language learning App ICE in a college level Mandarin course. Vocabulary exercises were assigned in ICE, whilst more multimedia exercises and materials were easily assigned via WeChat. The proposed method allowed students to receive instant feedback from instructor and other students. The experimental result after a yearlong experiment showed that the proposed method is effective in helping students master language concepts. In the future, we plan to disseminate ICE and WeChat, collect more data and conduct data analytics. In general, the first-year Chinese language students who participated in this project expected that other instructors continue using these apps to assist Chinese language teaching in the next level Mandarin course. Among the different learning activities, students considered the video and audio exercises in WeChat as the most helpful and the writing experiences as the least helpful. The survey data showed that students perceived the App and the WeChat project to have helped them expand the time of learning Chinese, improve their Chinese linguistic skills, promote Chinese cultural learning, enhance Chinese language learning motivation, and create a supportive Chinese language learning community. The participants also identified a number of feedback and proposed suggestions for improvement.

Future studies may need to examine student production data as generated in the language learning process to assess the usefulness of ICE and WeChat more objectively. In using the App and WeChat in Chinese language teaching needs supplementary monitoring from the instructor. Ideally, every assignment using ICE and WeChat need to be planned and spelled out in the syllabus, ensuring that the assignment is systematically implemented in language teaching.

\section{References}

Prensky, M. (2001). Digital Natives, Digital Immigrants Part 1, On the Horizon, Vol. 9 Issue: 5, pp.1-6 https://doi.org/10.1108/10748120110424816

Turner, A. (2015). Generation Z: Technology and Social Interest. Journal of Individual Psychology. 71 (2): 103-113. doi:10.1353/jip.2015.0021 
Borca, G.; Bina, M.; Keller, P.; Gilbert, L.R.; Begotti, T. (1 November 2015). "Internet use and developmental tasks: Adolescents' point of view". Computers in Human Behavior. 52: 49 58. doi:10.1016/j.chb.2015.05.029

Wen. X.H. (2017). Challenge and Change in Teaching Chinese as the Second Languages in USA, Chinese Teaching in the World Journal 2017 Vol 4, pp 23-35

Stockwell, G. (2012). Computer-Assistant Language Learning, Cambridge University Press March 2012 ISBN 9781139060981

Burston, J., Mall (2014). The pedagogical Challenges, Computer Assisted Language Learning Journal Pages 344-357 Published 14 May 2014

Thornton, P., \& Houser, C., (2005). Using mobile phones in English education in Japan, Journal of Computer Assisted Learning 21, pp217-228, Blackwell Publishing Ltd 2005

Cherian, E.J, Williams, P. Mobile Learning: The Beginning of the End of Classroom Learning, Proceedings of the World Congress on Engineering and Computer Science, October 22 - 24 , 2008, San Francisco, USA

Chinnery,G.M. (2006). Emerging technologies going to the MALL: mobile assisted language learning Language, Learning and Technology Journal 10(1) · January 2006

Chinese Link, http://wps.prenhall.com/wl_wu_chinese_link_2nd_edition/

Kenney, C., \& Levy M. (2008). Using SMS to support beginners' language learning, European Association for Computer Assisted Language Learning, Vol. 20 (3), Sept. 2008 , pp. 315-330

Kukulska-Hulme, A. (2007). Mobile Usability in Educational Contexts: What have we learnt? International Review of Research in Open and Distributed Learning, Vol 8, No 2 (2007)

Power, T., \&Shrestha, P.N. (2009). Is there a role for mobile technologies in open and distance language learning? 8th International Languages and Development Conference, 23-25 June 2009

Wishart, J.M. (2008). Challenges faced by modern foreign language teacher trainees in using handheld pocket PCs (Personal Digital Assistants) to support their teaching and learning, ReCALL, vol 20(3), pp. 348 - 360.2008

Burston, J. (2014). The Reality of MALL: Still on the Fringes, CALICO Journal, Vol. 31, No. 1, 2014, pp. $103-125$

Brown, S. (2011). Second Language Acquisition Myths: Applying Second Language Research to Classroom Teaching 1st Edition, University of Michigan Press ELT; 1 edition (March 15, 2012)

Osman, M.,\&Chung, P. W (2011). Language learning using texting and wiki: a Malaysian context, e-CASE and e-Tec 2011

Chiang, D. (2013). The International Workshop on Language Preservation: An Experiment in Text Collection and Language Technology, Language Documentation and Conservation, Vol. 7 (2013), pp. 155-167

Cho, S. (2009). Smartphones used for foreign language learning. Multimedia-Assisted Language Learning, 12(3), 211-228.

Godwin-Jones, R. (2011). Emerging Technologies Autonomous Language, Language Learning \& Technology, October 2011, Volume 15, Number 3 pp. 4-11, 2011

Vesselinov, R. and J. Grego (2016). The Busuu Efficacy Study. http://comparelanguageapps.com/documentation/The_busuu_Study2016.pdf last access June 2019

Vesselinov, R. and J. Grego (2012).Duolingo Effectiveness Study. http://comparelanguageapps.com/documentation/DuolingoReport_Final.pdf, last access June 2019

Vesselinov, R. (2008). Measuring the Effectiveness of Rosetta Stone ${ }^{\circ}$. http://comparelanguageapps.com/documentation/MeasuringTheAttitudeandMotivationofRSUse

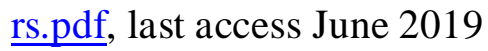

